\title{
Isolation of Brucella melitensis from Breast Tissue: A Case Report \\ Y Beşli $1^{1,2}$, O Karatuna $^{1,3}$, F Aksoy $^{4}$, I Akyar ${ }^{1,3}$
}

\begin{abstract}
Brucellosis is a zoonotic infectious disease caused by the bacterial genus Brucella. It may affect several species of domestic and wild animals, as well as humans and considered one of the most common zoonotic diseases worldwide. The organism has the ability to survive in the intracellular environment, contained within polymorphonuclear cells and macrophages. The infection may be localized or systemic and soft tissue involvement is one of the rare presentations of localized brucellosis. Brucellosis in breast tissue, however is quite rare in human infections. These rare and nonspecific forms of brucellosis pose diagnostic challenges to clinicians.
\end{abstract}

In this study, in an attempt to draw attention about rare forms of brucellosis, we report a case of 51 years old female with brucellosis manifests as breast involvement. The patient presented with a breast mass which caused tenderness, redness and warmth around the mass on the left breast. Brucella spp. was isolated from the biopsy specimen and the diagnosis was confirmed by a polymerase chain reaction test. Additionally Brucella Rose Bengal test and Wright agglutination test (titer $\geq 1 / 1280$ ) were found positive. Treatment with combination of doxycycline and rifampicin for a duration of eight months resulted in clinical cure.

Brucellosis should be considered in cases with nonspecific signs and symptoms, especially in the presence of sociodemographic risk factors. Agglutination tests in the diagnosis of brucellosis is a cost-effective diagnostic tool with rapid turnaround time. Although recovering Brucella spp. from microbiological cultures is essential for a definitive diagnosis, a molecular method such as PCR might be helpful in differential diagnosis.

Key words: Brucellosis, Brucella, localized brucellosis, breast involvement

From: ${ }^{1}$ Acıbadem Labmed Clinical Laboratories, Microbiology Department, Istanbul, Turkey. ${ }^{2}$ Vocational School of Health Services,Acıbadem University, Istanbul Turkey. ${ }^{3}$ Acıbadem University School of Medicine, Department of Medical Microbiology, Istanbul, Turkey. ${ }^{4}$ Karadeniz Technical University School of Medicine, Department of Infectious Diseases and Clinical Microbiology, Trabzon, Turkey.

Correspondence: Dr Y Beşli, Acıbadem Labmed Klinik Laboratuvarları, Acıbadem Üniversitesi Kerem Aydınlaampüsü, İçerenköy Mah. Kayışdağ Cad. No:32-B, 34752, Ataşehir, İstanbul, Türkiye. Fax: +90 216 576 1904, e-mail: yesim.besli@acibademlabmed.com.tr 


\section{INTRODUCTION}

Soft tissue manifestation is one of the rare forms of localized brucellosis. Furthermore, breast involvement in the course of the disease is quite uncommon in humans (1). Clinical diversity and nonspecific manifestations of the disease may result in misdiagnosis (2). Identification of organ involvement is particularly important for the management of diagnosis, treatment, and prognosis of the disease, especially in the case of rare and nonspecific clinical manifestations (3). In this study, we aimed to report an unusual presentation of brucellosis which manifests as breast involvement.

\section{CASE REPORT}

We describe a 51 years old woman with a breast mass causing tenderness, redness and warmth around the mass on the left breast. The patient also had systemic symptoms such as weakness, night sweats and fever which started ten days before the breast mass was noticed. The patient living in a rural area of Black Sea region in Turkey was dealing with livestock raising. No other specific symptoms were noted during physical examination.

Laboratory test results were as follows; mild leukopenia and neutropenia $\left(4.49 \times 10^{3} / \mu \mathrm{L}\right.$ leukocytes; 42.5\% neutrophils, 43.9\% lymphocytes, 10.7\% monocytes, $2.7 \%$ eosinophil, $0.2 \%$ basophil), relatively elevated transaminases (ALT: $27 \mathrm{U} / \mathrm{L}$ and AST: $41 \mathrm{U} / \mathrm{L}$ ). Erythrocyte sedimentation rate $(15 \mathrm{~mm} /$ hour $)$ and C-reactive protein level $(0.16 \mathrm{mg} / \mathrm{dL})$ were found within normal limits. The bilateral breast ultrasound examination revealed a lobular contoured hyperechogen lesion $27.5 \times 19 \times 19 \mathrm{~mm}$ in diameter on the external inferior quadrant of the left breast. 
On color Doppler ultrasonographic examination, a solid lesion showing increased vascularisation was detected. A specimen obtained by ultrasonography-guided core needle biopsy was sent for pathological and microbiological examination. The pathological examination revealed abscess formation and granulation tissue formation in the specimen, whereas in the microbiology laboratory Brucella spp. was cultured from the biopsy specimen. The organism was identified as Brucella melitensis by the VITEK 2 instrument using GN identification card (bioMérieux, France). The organism was also identified as Brucella spp. by the in-house polymerase chain reaction (PCR) test. The serological diagnosis of the infection was documented by a positive Rose Bengal test and Wright agglutination test (titer $\geq 1 / 1280$ ) results.

The patient was prescribed doxycycline $200 \mathrm{mg} /$ day and rifampicin $600 \mathrm{mg} / \mathrm{day}$. The abscess and other systemic symptoms of the patient had clinically disappeared. Wright agglutination test titer was reduced to $1 / 160$ and also on control ultrasound examination at the end of 8 weeks there was no significant finding related to the abscess.

\section{DISCUSSION}

Brucellosis is among the most common zoonotic diseases worldwide (4). From Turkey, which shares borders with endemic countries such as Syria, Iran, and Greece, 4475 cases were reported in 2014 (5). Brucellosis is considered endemic in the eastern regions of Turkey where socioeconomical status is low (4).

Unpasteurized dairy products are the main cause for the transmission of disease, especially in endemic areas. Raw dairy product consumption rates are reported to be between $62.6 \%$ and $94.6 \%$ in Turkey. Individuals engaged in livestock, butchery, farming, veterinary, and also laboratory workers are at high risk for brucellosis in developed countries. Buzgan et al. (6) 
characterized 1028 brucellosis patients in Van region, where the disease is highly prevalent and reported that $42.3 \%$ of patients had a history of raising livestock; $52 \%$ were female and $69.6 \%$ were between 13-44 years old. The typical symptoms were arthralgia and fever; prevalent clinical signs were fever and hepatomegaly. The most common complication was osteoarticular involvement (25.3\%) and local infiltrations were observed in $36.1 \%$ of patients (6). Focal involvement occurs with direct contact or haematogenous spread of the bacteria. Mammary infiltration is extremely rare in human infections even though it is common in animals (7).

To the best of our knowledge, there are as low as seven cases of mammary abscess and two cases of breast implant infection in humans due to Brucella spp. reported in the literature, interestingly four of these cases being reported from Turkey (1, 7-13). Breast abscess in two of the cases was bilateral and lymphadenopathy was also detected $(9,10)$. In two of the cases, some other accompanying localized manifestations such as unilateral posterior uveitis and vertebral bone abscess were also noted (7). Additionally, in one case, systemic brucellosis was diagnosed and in another case accompanying hepatomegaly was detected $(1,7)$. One of the cases was a pregnant woman (7). All patients had nonspecific laboratory findings except for positive agglutination test results. Radiological findings were indicative for abscess formation but they were erroneously evaluated in favour with malignant mass in some cases. Doxycycline and rifampicin, doxycycline and streptomycin, or rifampicin and tetracycline combinations were the chosen regimens as the antimicrobial therapy $(1,7,8,14,15)$. In contrast with other cases, in our case no systematic or local finding suggestive of brucellosis infection was noted, also laboratory tests, except for the agglutination tests, were nonspecific.

Even though half a million human brucellosis cases are being reported annually, these numbers don't reflect the actual number of infected individuals. World Health Organization predicts that these numbers are 10-25 times higher than being reported (16). 
The main causes of the big gap between the diagnosed and the actual case numbers are identified as failures in recognition and treatment of the patients as "fever of unknown origin" in most of the cases. Although brucellosis is a preventable and curable disease, failure in correct diagnosis and delay in the initiation of appropriate therapy is relatively common. While clinical symptoms and physical examination findings are nonspecific, radiological methods and laboratory findings, except for microbiological tests, are of little utility for the diagnosis (16).

\section{CONCLUSION}

Our case presentation supports the clinical utility of agglutination tests in the diagnosis of brucellosis as a cost-effective diagnostic tool with rapid turnaround time. Although recovering Brucella spp. from microbiological cultures is essential for a definitive diagnosis, in the presence of serological evidence for brucellosis in unusual clinical presentations, the confirmation of negative culture results by a molecular method such as PCR might be helpful in differential diagnosis. 


\section{REFERENCES}

1. Erdem G, Karakas HM, Yetkin F, Alkan A, Firat AK, Kahraman B. Brucellar breast access. Breast 2006; 15: 554-557.

2. Franco MP, Mulder M, Gilman RH, Smits HL. Human brucellosis. Lancet Infect Dis 2007; 7: 775-786.

3. Doganay M, Aygen B. Human brucellosis: an overview. Int J Infect Dis 2003; 7: 173-182.

4. Pappas G, Papadimitriou P, Akritidis N, Christou L, Tsianos EV. The new global map of human brucellosis. Lancet Infect Dis 2006; 6: 91-99.

5. World Organization for Animal Health Zoonoses in Humans [Internet]. Available from: http://www.oie.int/wahis_2/public/wahid.php/Countryinformation/Zoonoses.

6. Buzgan T, Karahocagil MK, Irmak H, Baran AI, Karsen H, Evirgen O, et al. Clinical manifestations and complications in 1028 cases of brucellosis: a retrospective evaluation and review of the literature. Int J Infect Dis 2010; 14: 469-478.

7. Gurleyik E. Breast abscess as a complication of human brucellosis. Breast J 2006; 12: $375-6$.

8. Akay H, Girgin S, Ozmen CA, Kilic I, Sakarya H. An unusual bilateral mastitis in a postmenopausal woman caused by brucellosis. Acta Chir Belg 2007; 107: 320-322.

9. Gasser I, Alrnirante B, Fernfindez-Perez F, Mendoza C. Bilateral Mammary Abscess and Uveitis Caused by Brucella melitensis- Report of a Case. Infection 1991;19:44-5.

10. AI Abdely HM, Halim MA and Amin TM. CASE REPORT Breast Abscess Caused by Brucella mefitensis. Journal of Infection 1996; 33: 219-220.

11. Cokca F, Azap A and Meco O. Bilateral Mammary Abscess due to Brucella melitensis. Scand J Infect Dis 1999; 31: 318-319. 
12. Ziad A. Memish, M. Alazzawi, R. Bannatyne. Unusual Complication of Breast Implants: Brucella Infection. Infection 2001; 29: 291-292.

13.. Tsironi M, Andriopoulos P, Kalkanic M,Asimakopoulos G. Human mammary abscess caused by Brucella melitensis: a case report. Int J Infect Dis 2003; 7: 236.

14. De BK, Stauffer L, Koylass MS, Sharp SE, Gee JE, Helsel LO, et al. Novel Brucella strain (BO1) associated with a prosthetic breast implant infection. J Clin Microbiol 2008; 46: 43-9.

15. Al Dahouk S, Nöckler K. Implications of laboratory diagnosis on brucellosis therapy. Expert Rev Anti Infect Ther 2011; 9: 833-845.

16. Al Dahouk S, Nöckler K. Implications of laboratory diagnosis on brucellosis therapy. Expert Rev Anti Infect Ther 2011; 9: 833-845. 